\title{
PENGARUH SELF-ESTEEM DAN HUMOR STYLE TERHADAP PSYCHOLOGICAL WELL-BEING PADA PELAJAR SMAN 72 JAKARTA
}

\author{
Setika Jati Aminrais \\ masssrais@gmail.com \\ Fakultas Psikologi UIN Syarif Hidayatullah Jakarta
}

\begin{abstract}
This research is conducted to discover selfesteem, humor style and gender effects toward psycological well-being over SMAN 72 Jakartas's students. Sample data of this research is SMAN 72 Jakarta's students as much as 272 students. Sampling technique that been used is probability sampling. Data analysis that been used is multiple regression analysis on significant level 0,05 . Result of this research point that there are significant effects of self-esteem, humor style, and gender toward psychological well being over SMAN 73 Jakarta's students. Variant propotion from psychological well-being that been explain from all independent variable are 19,2\%, while the rest 80,8\% effected by othe variable from outside of this research. Result of minor hypotesis test point that dimentions of value on self-esteem variable, and three type of humor style, which is afflictive humor, aggressive humor and self-enhancing humor having significant effect toward psychological well-being. Meanwhile, successes dimension, aspirations and defences on self-esteem variable, self-enhancing humor type, and gender are not having significant effect
\end{abstract}

Keywords: psychological well-being, self-esteem, humor style, gender

\begin{abstract}
Abstrak
Penelitian ini dilakukan untuk mengetahui pengaruh self-esteem, humor style dan jenis kelamin terhadap psychological well-being pada Pelajar SMAN 72 Jakarta. Sampel dala penelitian ini adalah siswa-siswi SMAN 72 Jakarta sebanyak 272 orang. Teknik sampling yang digunakan adalah probability sampling. Analisis data yang digunakan adalah multiple regresi analisis pada taraf signifikansi 0,05 . Hasil penelitian menunjukan bahwa ada pengaruh yang signifikan self-esteem, humor style dan jenis kelamin terhadap psychological well-being pada Pelajaran SMAN 72 Jakarta. Proporsi varians dari psychological well-being yang dijelaskan oleh semua independent variable adalah sebesar $19,2 \%$, sedangkan $80,8 \%$ sisanya dipengaruhi oleh variabel lain diluar penelitian ini. hasil uji hipotesis minor menunjukkan bahwa dimensi values pada variabel self-esteem dan tiga tipe humor style, yaitu affiliative humor, aggressive humor dan self-enhancing humor memiliki pengaruh yang signifikan terhadapat psychological well-being. Sementara itu, dimensi successes, aspirations dan defences pada variabel self-esteem, tipe humor
\end{abstract}


style self-enhancing dan jenis kelamin tidak memiliki pengaruh yang signifikan.

Kata kunci: psychological well-being, self-esteem, humor style, jenis kelamin

\section{PENDAHULUAN}

Kesehatan merupakan salah satu kebutuhan dasar manusia disamping pangan, pemukiman dan pendidikan, karena hanya dalam keadaan sehat manusia dapat hidup, tumbuh dan berkarya lebih baik untuk mencapai aktualisasi diri dalam hidupnya. Banyak masyarakat yang memiliki konsep bahwa kesehatan hanya dipandang sebagai keadaan sehat secara fisik saja dan menomer duakan sisi psikis. Padahal Badan Kesehatan Dunia (WHO) mendefinisikan kesehatan adalah keadaan yang menyeluruh dari fisik, mental dan kesejahteraan sosial, bukan hanya tidak terdapat penyakit atau kelemahan (dalam Juliet, Tom dan Steven, 2011).

Berdasarkan data WHO pada tahun 2002, sedikitnya ada 154 juta orang di seluruh dunia yang mengalami depresi. Di Indonesia, remaja di bawah usia 15 tahun yang mengalami depresi berdasarkan data Kemenkes pada tahun 2007 mencapai sekitar 19 juta orang (dalam Pramudiarja, 2012). Angka tersebut bukanlah jumlah yang sedikit, hal tersebut tentunya membutuhkan usaha khusus yang harus dilakukan oleh pemerintah dan masyarakat guna menekan jumlah prevalensi depresi yang terjadi di Indonesia.

Mardiya (2011) menambahkan ciri-ciri adanya masalah psychological well-being pada pelajar remaja ditandai dengan munculnya gejala seperti sulit untuk konsentrasi, sering merasa putus asa, gairah belajar berkurang, sulit mengambil keputusan, tidak ada inisiatif, sering merasa sedih, suka menyendiri, sering melamun di dalam kelas atau di rumah, mengalami ganguan tidur dan merasa rendah diri. Selain itu pelajar yang memiliki masalah psychological well-being akan memperlihatkan kreativitas, inisiatif dan motivasi belajar yang menurun, sehingga akan menimbulkan kesulitan belajar dan membuat prestasi belajar anak menurun dari waktu ke waktu. Oleh sebab itu penting bagi pelajar untuk memiliki psychological well-being yang baik, agar tercegah dari dampak buruk tersebut.

Munculnya masalah seperti menurunya prestasi belajar, gairah belajar berkurang, rendahnya motivasi belajar, kesulitan untuk memahami pelajaran, sering merasa sedih, suka menyendiri, sering melamun di dalam kelas dan merasa rendah diri. Itu semua merupakan ciri adanya masalah psychological well-being pada pelajar yang sangat umum ditemui, termasuk di SMAN 72 Jakarta.

Tinggi rendahnya psychological well-being dipengaruhi oleh banyak faktor. Ryff (dalam Keyes, Shmotkin, dan Ryff, 2002) menjelaskan ada 
banyak faktor yang mempengaruhi psychological well-being seseorang, antara lain: kepuasan hidup, spiritualitas, optimisme, kebahagiaan, kedewasaan, hubungan dengan orang lain, self-autonomy, usia seseorang, jenis kelamin, status sosial, budaya, faktor dukungan sosial, self-esteem dan humor style.

Penelitian mengenai psychological well-being memang sudah banyak dilakukan di negara luar dan yang menjadi subjek di dalam penelitiannya adalah orang dewasa. Sehingga informasi mengenai psychological well-being pada pelajar remaja masih kurang. Adanya fenomena masalah menurunya prestasi belajar, gairah belajar berkurang, rendahnya motivasi belajar siswa SMAN 72 Jakarta mendorong peneliti untuk melakukan penelitian ini. Untuk menguji validitas dan reliabilitas dari hasil penelitian sebelumnya. Dari berbagai faktor yang mempengaruhi psychological well-being, peneliti hanya memfokuskan pada self-esteem dan humor style sebagai faktor yang mempengaruhinya.

Berdasarkan latar belakang tersebut, peneliti akan melakukan penelitian dengan judul "Pengaruh self-esteem dan humor style terhadap psychological well-being pada Pelajar Sekolah Menengah Atas Negeri 72 Jakarta".

\section{KAJIAN TEORI}

\section{Teori dan Hipotesis}

Psychological well-being adalah perasaan seseorang mengenai aktivitas hidup sehari-hari. Perasaan ini dapat berkisar dari kondisi mental negatif, misalnya ketidakpuasan hidup, kecemasan, dan sebagainya sampai ke kondisi mental positif, misalnya realisasi potensi atau aktualisasi diri (Ryff, 1996).

Menurut Ryyff (1996) psychological well-being memiliki 6 dimensi, yaitu:

a. Penerimaan diri (self acceptance) adalah salah satu karakter dari individu yang mampu mengaktualisasikan dirinya dan mereka dapat menerima diri apa adanya, memberikan penilaian yang tinggi pada individualitas dan keunikan diri sendiri.

b. Hubungan positif dengan orang lain adalah kemampuan untuk mencintai dan membina hubungan interpersonal yang dibangun atas dasar saling percaya, simpati, kasih sayang dan persahabatan.

c. Otonomi adalah kemampuan untuk menentukan nasib sendiri (selfdetermination), bebas dan memiliki kemampuan untuk mengatur perilaku sendiri.

d. Penguasaan lingkungan adalah kemampuan individu untuk memilih, menciptakan dan mengelola lingkungan agar sesuai dengan kondisi psikologisnya dalam rangka mengembangkan diri. 
e. Tujuan hidup adalah pemahaman yang jelas akan tujuan hidup yang dijalaninya dan memiliki keyakinan yang dapat memberikan makna dan arah bagi kehidupannya.

f. Pertumbuhan pribadi adalah keinginan untuk terus mengembangkan potensinya, tumbuh sebagai individu dan dapat berfungsi secara penuh (fully functioning).

Self-esteem adalah penilaian terhadap diri sendiri (personal judgment) mengenai perasaan mampu, penting, berarti dan menerima kekurangan yang ada dan yang diekspresikan dalam sikap-sikap individu terhadap dirinya.

Menurut Coopersmith (1990) self-esteem memiliki empat dimensi, yaitu:

a. Successes atau keberhasilan adalah tingkat pencapaian yang tinggi, dengan tingkatan, dan tugas yang bervariasi untuk setiap individu.

b. Values adalah nilai-nilai yang ada didalam diri individu, terinternalisasi dari lingkungan yang membawanya untuk menerima standar nilai dan standar nilai tersebut menjadi prinsip dasar untuk menilai keberartian dirinya.

c. Aspirations adalah harapan dan tujuan untuk keberhasilan pada masa yang akan datang. Aspiration terkait dengan self expectancy, sikap asertif, self trust, dan keinginan kuat untuk bereksplorasi.

d. Defences adalah kemampuan untuk mengeliminir stimulus yang mencemaskan, mampu menjaga ketenangan diri dan tingkah lakunya efektif.

Humor style adalah kebervariasian individu dalam menggunakan humor di kehidupannya sehari-hari yang cederung konsisten dan humor style dapat sedikit berbeda tergantung pada situasi, tetapi cenderung menjadi karakteristik kepribadian yang relatif stabil di antara individu.

Menurut Martin (2007) humor style memiliki empat tipe, yaitu:

a. Affiliative humor adalah kecenderungan seseorang menggunakan humor untuk menghibur orang, untuk meningkatkan hubungan dan untuk meredakan ketegangan intrapersonal.

b. Self-enhancing humor adalah kecenderungan seseorang menggunakan perspektif humor sebagai regulasi emosi atau mekasinme coping saat menghadapi stres atau kemalangan.

c. Aggressive humor adalah kecenderungan mengekspesikan humor tanpa memikirkan dampaknya pada orang lain. Contohnya seperti melontarkar sindiran, ejekan, cemooh atau humor yang bersifat meremehkan dan menghina orang lain.

d. Self-defeating humor adalah humor yang bersifat sangat menghina diri sendiri, berusaha untuk menghibur orang lain dengan melakukan atau mengatakan hal-hal yang lucu mengenai diri sendiri, agar bisa

e. mengambil hati orang-orang disekitarnya. 


\section{Hipotesis Penelitian}

Ada pengaruh yang singnifikan self-esteem (successes, value, aspirations dan defences), humor style (affiliative humor, self-enhancing humor, aggressive humor dan self-defeating humor), dan variabel demografis jenis kelamin terhadap psychological well-being pelajar SMAN 72 Jakarta.

\section{Hipotesis Minor}

$\mathrm{H}_{1} \quad$ : Ada pengaruh yang signifikan dimensi successes pada variabel self esteem terhadap psychological well-being.

$\mathrm{H}_{2} \quad$ : Ada pengaruh yang signifikan dimensi value pada variabel selfesteem terhadap psychological well-being

$\mathrm{H}_{3} \quad$ : Ada pengaruh yang signifikan dimensi aspirations pada variabel self-esteem terhadap psychological well-being

$\mathrm{H}_{4} \quad$ : Ada pengaruh yang signifikan dimensi defences pada variabel selfesteem terhadap psychological well-being

$\mathrm{H}_{5} \quad$ : Ada pengaruh yang signifikan dimensi affiliative humor pada variabel humor style terhadap psychological well-being.

$\mathrm{H}_{6} \quad$ : Ada pengaruh yang signifikan dimensi self-enhancing humor pada variabel humor style terhadap psychological well-being.

$\mathrm{H}_{7} \quad$ : Ada pengaruh yang signifikan dimensi aggressive humor pada variabel humor style terhadap psychological well-being.

$\mathrm{H}_{8} \quad$ : Ada pengaruh yang signifikan dimensi self-defeating humor pada variabel humor style terhadap psychological well-being.

$\mathrm{H}_{9} \quad$ : Ada pengaruh yang signifikan variabel demografis jenis kelamin terhadap psychological well-being.

\section{METODE PENELITIAN}

\section{Pupulasi dan sampel}

Populasi dalam penelitian ini adalah siswa-siswi SMAN 72 Jakarta kelas X, XI dan XII. Jumlah populasi siswa tahun ajaran 2013-2014 sejumlah 782 siswa, yang terdiri atas 247 siswa kelas X, 258 siswa kelas XI dan 277 siswa kelas XII. Dari jumlah tersebut peneliti menetapkan sampel sebanyak 272 siswa atau 35\% dari jumlah populasi. Penetapan jumlah sampel tersebut disesuaikan dengan kemampuan peneliti berdasarkan pertimbangan waktu dan dana dalam penelitian ini.

Pengambilan sampel pada penelitian ini menggunakan teknik probability sampling, dimana peneliti memberikan kesempatan yang sama kepada semua anggota populasi untuk ditetapkan sebagai anggota sampel. Peluangnya anggota populasi yang menjadi sampel bisa dihitung atau diketahui. Dalam menentukan sampel peneliti menggunakan software SPSS versi 18.0 untuk memilih secara acak sampel dari populasi. 


\section{Variabel penelitian}

Adapun variabel-variabel dalam penelitian ini, diantaranya:

1. Dependent variable : Psychological well-being

2. Independent variable : Self-esteem (successes, value, aspirations dan defences), humor style (affiliative humor, self-enhancing humor, aggressive humor dan self-defeating humor) dan jenis kelamin.

Tabel 1

Uji validitas konstruk

\begin{tabular}{|c|c|c|c|c|}
\hline $\begin{array}{l}\text { Instrume } \\
\mathrm{n}\end{array}$ & Dimensi & No. Item & $\begin{array}{l}\text { No. Item } \\
\text { Tdk Valid }\end{array}$ & $\begin{array}{l}\text { No. Item } \\
\text { Valid }\end{array}$ \\
\hline \multirow[t]{6}{*}{ PWB } & $\begin{array}{l}\text { Penerimaan } \\
\text { diri }\end{array}$ & $6,12,18,24,30,36,42$ & - & $6,12,18,24,30,36,42$ \\
\hline & Hub dgn org & $4,10,16,22,28,34,40$ & 10 & $4,16,22,28,34,40$ \\
\hline & Otonomi & $1,7,13,19,25,31,37$ & 7,37 & $1,13,19,25,31$ \\
\hline & $\begin{array}{l}\text { Penguasaan } \\
\text { ling. }\end{array}$ & $2,8,14,20,26,32,38$ & 8,38 & $2,14,20,26,32$ \\
\hline & Tujuan hidup & $5,11,17,23,29,35,41$ & 41 & $5,11,17,23,29,35$ \\
\hline & $\begin{array}{l}\text { Pertum } \\
\text { Pribadi }\end{array}$ & $3,9,15,21,27,33,39$ & 27 & $3,9,15,21,33,39$ \\
\hline \multirow{4}{*}{$\begin{array}{l}\text { Self- } \\
\text { Esteem }\end{array}$} & Successes & $1,2,3,4,5,6,7,8,9,10$ & - & $1,2,3,4,5,6,7,8,9,10$ \\
\hline & Values & $11,12,13,14,15$ & 12 & $3,9,15,27,33,39$ \\
\hline & Aspiration & $16,17,18,19,20$ & 20 & $16,17,18,19$ \\
\hline & Defences & $21,22,23,24,25$ & 22,25 & $21,23,24$ \\
\hline \multirow[t]{4}{*}{$\begin{array}{l}\text { Humor } \\
\text { Style }\end{array}$} & Affiliative & $1,5,9,13,17,21,25,29$ & - & $\begin{array}{l}1,5,9,13,17,21,25,2 \\
9\end{array}$ \\
\hline & $\begin{array}{l}\text { Self- } \\
\text { enhancing }\end{array}$ & $26,10,14,18,22,26,30$ & - & $\begin{array}{l}26,10,14,18,22,26,3 \\
0\end{array}$ \\
\hline & Aggressive & $3,7,11,15,19,23,27,31$ & $3,7,23,27,31$ & $11,15,19$ \\
\hline & $\begin{array}{l}\text { Self- } \\
\text { defeating }\end{array}$ & $4,8,12,16,20,24,28,32$ & - & $\begin{array}{l}4,8,12,16,20,24,28 \\
32\end{array}$ \\
\hline Total & & 99 & 16 & 83 \\
\hline
\end{tabular}

\section{Instrument Pengumpulan Data}

Dalam penelitian ini peneliti mengunakan tiga skala, yaitu:

1. Ryff's Psychological Well-being Scale 42 Version yang terdiri dari 42 item.

2. The School Short-form Coopersmith Self-esteem Inventory yang terdiri dari 25 item.

3. Humor Style Questioner yang terdiri dari 32 item. 


\section{Ujian Validitas Konstruk}

Untuk menguji keadaan instrumen yang digunakan pada penelitian ini, maka dilakukan uji validitas dengan menggunakan CFA (Confirmatory Factor Analysis).

\section{Tabel 1 Hasil Uji Validitas Konstruk}

Berdasarkan data pada tabel 1 menunjukan bahwa dari hasil uji konstruk yang dilakukan dari tiga alat ukur yang digunakan dalalam penelitian ini 16 item dinyatakan tidak valid $(t<1,96)$ dan 83 item lainnya valid $(\mathrm{t}>1,96)$.

\section{METODE PENELITIAN DATA}

\section{Metode Analisis Data}

Analisis data adalah proses penelaahan data agar dapat ditafsirkan. Tujuan dari penafsiran tersebut adalah untuk memberikan makna pada data yang diperoleh dan menjelaskan pola atau kategori, kemudian mencari hubungan antara berbagai konsep. Pengolahan data dilakukan dengan analisa data secara statistik sebagai cara untuk mengetahui pengaruh variabel bebas (independent variable) yaitu: self-esteem (successes, value, aspirations dan defences) dan humor style (affiliative humor, self-enhancing humor, aggressive humor dan self-defeating humor) terhadap variabel terikat (dependent variable) yaitu psychological well-being.

Dalam rangka menjawab pertanyaan penelitian yaitu apakah terdapat pengaruh yang signifikan independent variable terhadap dependent variable, maka penulis menggunakan metode statistika, karena datanya berupa angka-angka yang merupakan hasil pengukuran atau perhitungan. Dalam hal ini hipotesis yang akan diukur, penulis menggunakan teknis analisis multiple regression atau analisis regresi berganda. 


\section{HASIL PENELITIAN}

\section{Tabel 2}

\section{Anova Pengaruh Keseluruhan IV Terhadap DV}

\begin{tabular}{clllccc}
\hline & Model & Sum of Squares & Df & Mean Square & F & Sig. \\
\hline 1 & Regression & 10319.041 & 9 & 1146.560 & 6.916 & $.00^{\mathrm{a}}$ \\
& Residual & 43433.369 & 262 & 165.776 & & \\
& Total & 53752.410 & 271 & & & \\
\hline
\end{tabular}

a. Predictors: (Constant), Jenis Kelamin, Enhancing, Sukses, Defeating, Aspiration, Affiliative, Defences, Value, Aggressive

a. Dependent Variable: PWB

Berdasarkan data pada tabel 2 kolom ke 6 dari kiri diketahui bahwa $(p<0.05)$ atau signifikan, maka hipotesis nol ditolak. Oleh karenanya hipotesis minor yang menyatakan ada pengaruh yang signifikan seluruh independent variable terhadap perilaku psychological well-being diterima. Artinya, ada pengaruh yang signifikan dari self-esteem (successes, value, aspirations dan defences), humor style (affiliative humor, self-enhancing humor, aggressive humor dan self-defeating humor), dan variabel demografis jenis kelamin terhadap psychological well-being.

Langkah terakhir adalah melihat koefisien regresi tiap independent variable. Jika nilai $\mathrm{t}>1,96$ maka koefisien regresi tersebut signifikan yang berarti bahwa IV tersebut memiliki dampak yang signifikan terhadap psychological well-being. Adapun penyajiannya ditampilkan pada tabel 3

\section{Tabel 3.}

\section{Koefisien Regresi}

Coefficients $^{\mathrm{a}}$

\begin{tabular}{|c|c|c|c|c|c|c|}
\hline & \multirow[t]{2}{*}{ Model } & \multicolumn{2}{|c|}{ Unstandardized Coefficients } & $\begin{array}{l}\text { Standardized } \\
\text { Coefficients }\end{array}$ & \multirow[b]{2}{*}{$\mathrm{T}$} & \multirow[b]{2}{*}{ Sig. } \\
\hline & & $\mathrm{B}$ & Std. Error & Beta & & \\
\hline 1 & (Constant) & 22.547 & 6.335 & & 3.559 & .000 \\
\hline & Sukses & .093 & .073 & .085 & 1.264 & .207 \\
\hline & Value & .238 & .080 & .197 & 2.967 & .003 \\
\hline & Aspiration & -.001 & .067 & -.001 & -.009 & .993 \\
\hline & Defences & .049 & 059 & .052 & .824 & 411 \\
\hline & Affiliative & .204 & .067 & .191 & 3.035 & .003 \\
\hline & Enhancing & -.022 & .073 & -.020 & -.300 & .765 \\
\hline & Aggressive & .251 & .080 & .213 & 3.127 & .002 \\
\hline & Defeating & -.239 & .067 & -.225 & -3.565 & .000 \\
\hline & Jenis kel. & -2.009 & 1.669 & -.070 & -1.203 & .230 \\
\hline
\end{tabular}

a. Dependent Variable: PWB 
Berdasarkan koefisien regresi pada tabel 3 dapat disampaikan persamaan regresi sebagai berikut:

\section{$\mathrm{PWB}=22,547+0.085$ sukses $+0,197$ value $-0,001$ aspiration $+0,052$ defences $+0,191$ affiliative humor $-0,020$ self-enhancing humor $+0,213$ aggressive humor $-0,225$ defeating humor $-0,070$ jenis kelamin}

Berdasarkan data pada tabel 3 tersebut untuk melihat signifikan atau tidaknya koefisien regresi yang dihasilkan, kita cukup melihat nilai signifikan pada kolom yang paling kanan (kolom ke-6) jika $\mathrm{P}<0.05$, maka koefisien regresi yang dihasilkan signifikan pengaruhnya terhadap psychological well-being dan sebaliknya. Dari hasil di atas koefisien regresi dari value, affiliative humor, agrresive humor dan defeating humor dikatakan memiliki pengaruh yang signifikan sedangkan sisa lainnya tidak signifikan.

Hal ini berarti bahwa dari 9 independent variable hanya value, affiliative humor, agrresive humor dan defeating humor yang signifikan. Penjelasan dari nilai koefisien regresi yang diperoleh pada masing-masing IV adalah sebagai berikut:

1. Variabel succsess: diperoleh nilai koefisien regresi sebesar +0.085 succsess dengan nilai P-value sebesar 0,207 ( $p>0,05)$, yang berarti bahwa succsess tidak memiliki pengaruh yang signifikan terhadap psychological well-being.

2. Variabel values: diperoleh nilai koefisien regresi sebesar $+0,197$ dengan nilai $\mathrm{P}$-value sebesar $0,003(\mathrm{p}<0,05)$, yang berarti bahwa values memiliki pengaruh positif yang signifikan terhadap psychological well-being. Dapat disimpulkan, semakin tinggi values maka semakain tinggi psychological well-being.

3. Variabel aspirations: diperoleh nilai koefisien regresi sebesar 0,001 dengan P-value sebesar 0,993 ( $p>0.05$ ), yang berarti bahwa asprations tidak memiliki pengaruh yang signifikan terhadap psychological well-being.

4. Variabel defences: diperoleh nilai koefisien regresi sebesar $+0,052$ dengan P-value sebesar 0,441 ( $p>0,05)$, yang berarti bahwa defences tidak memiliki pengaruh yang signifikan terhadap psychological well-being.

5. Variabel affiliative humor: diperoleh nilai koefisien regresi sebesar $+0,191$ dengan P-value sebesar $0.03(\mathrm{p}<0,05)$, yang berarti bahwa affiliative humor memiliki pengaruh positif yang signifikan terhadap psychological well-being. Dapat disimpulkan, semakin tinggi affiliative humor maka semakain tinggi psychological wellbeing. 
6. Variabel self-enhancing humor: diperoleh nilai koefisien regresi sebesar -0,020 dengan P-value sebesar 0,765 ( $\mathrm{p}>0,05)$, yang berarti bahwa self-enhancing humor tidak memiliki pengaruh yang signifikan terhadap psychological well-being.

7. Variabel aggressive humor: diperoleh nilai koefisien regresi sebesar $+0,213$ dengan $\mathrm{P}$-value sebesar 0,002 ( $\mathrm{p}<0,05)$, yang berarti bahwa aggressive humor memiliki pengaruh positif yang signifikan terhadap psychological well-being. Dapat disimpulkan, semakin tinggi aggressive humor maka semakain tinggi psychological well-being.

8. Variabel self-defeating humor: diperoleh nilai koefisien regresi sebesar - 0,225 dengan P-value sebesar 0,000 ( $p<0,05)$, yang berarti bahwa self-defeating humor memiliki pengaruh negatif yang signifikan terhadap psychological well-being. Nilai koefisien regresi yang negatif menunjukan arah hubungan yang negatif antara self-defeating humor dan psychological well-being. Dari arah hubungan tersebut dapat diartikan jika skor self-defeating seseorang itu rendah makan skor psychological well-being-nya akan tinggi atau pun sebaliknya.

9. Variabel jenis kelamin : diperoleh nilai koefisien regresi sebesar $0,070$ dengan $\mathrm{P}$-value sebesar 0,230 ( $p>0,05)$, yang berarti bahwa jenis kelamin tidak memiliki pengaruh yang signifikan terhadap psychological well-being.

\section{Proporsi Varian}

Selanjutnya, peneliti ingin mengetahui bagaimana penambahan proporsi varians dari masing-masing independent variable terhadap psychological well-being. Pada tabel 3 kolom pertama adalah IV yang dianalisis secara satu per satu, kolom kedua merupakan penambahan varians DV dari tiap IV yang dianalisis satu per satu tersebut.

Kolom ketiga merupakan nilai murni varians DV dari tiap IV yang dimasukkan secara satu per satu, kolom keempat adalah nilai $\mathrm{F}$ hitung bagi IV yang bersangkutan, kolom DF adalah derajat bebas bagi IV yang bersangkutan pula, yang terdiri dari numerator dan denumerator, kolom $\mathrm{F}$ tabel adalah kolom mengenai nilai IV pada tabel $\mathrm{F}$ dengan DF yang telah ditentukan sebelumnya, nilai kolom inilah yang akan dibandingkan dengan kolom nilai $\mathrm{F}$ hitung.

Apabila nilai $\mathrm{F}$ hitung lebih besar daripada $\mathrm{F}$ tabel, maka kolom selanjutnya, yaitu kolom signifikansi yang akan dituliskan signifikan dan sebaliknya. Besarnya proporsi varians pada psychological well-being dapat dilihat pada table 4 berikut: 
Tabel 4.

Proporsi Varians untuk Masing-Masing Independent Variable (IV)

\begin{tabular}{|c|c|c|c|c|c|c|c|c|c|}
\hline \multirow[t]{2}{*}{ Model } & \multirow[b]{2}{*}{$\mathrm{R}$} & & & & \multicolumn{5}{|c|}{ Change Statistics } \\
\hline & & $\begin{array}{c}\mathrm{R} \\
\text { Square }\end{array}$ & $\begin{array}{l}\text { Adjusted R } \\
\text { Square }\end{array}$ & $\begin{array}{l}\text { Std. Error of } \\
\text { the Estimate }\end{array}$ & $\begin{array}{l}\text { R } \\
\text { Square } \\
\text { Change }\end{array}$ & $\begin{array}{c}\mathrm{F} \\
\text { Change }\end{array}$ & df1 & df2 & $\begin{array}{c}\text { Sig. F } \\
\text { Change }\end{array}$ \\
\hline 1 & $.245^{\mathrm{a}}$ & .060 & .056 & 13.68119 & .060 & 17.177 & 1 & 270 & .000 \\
\hline 2 & $.312^{\mathrm{b}}$ & .097 & .090 & 13.43177 & .037 & 11.120 & 1 & 269 & .001 \\
\hline 3 & $.315^{\mathrm{c}}$ & .099 & .089 & 13.44059 & .002 & .647 & 1 & 268 & .422 \\
\hline 4 & $.318^{\mathrm{d}}$ & .101 & .088 & 13.45240 & .002 & .530 & 1 & 267 & .467 \\
\hline 5 & $.368^{\mathrm{e}}$ & .136 & .119 & 13.21689 & .034 & 10.600 & 1 & 266 & .001 \\
\hline 6 & $.369^{f}$ & .136 & .117 & 13.23672 & .001 & .204 & 1 & 265 & .652 \\
\hline 7 & $.387^{\mathrm{g}}$ & .150 & .127 & 13.15524 & .014 & 4.293 & 1 & 264 & .039 \\
\hline 8 & $.433^{\mathrm{h}}$ & .188 & .163 & 12.88638 & .037 & 12.131 & 1 & 263 & .001 \\
\hline 9 & $.438^{\mathrm{i}}$ & .192 & .164 & 12.87541 & .004 & 1.448 & 1 & 262 & .230 \\
\hline \multicolumn{10}{|c|}{$\begin{array}{l}\text { a. Predictors: (Constant), SUKSES } \\
\text { b. Predictors: (Constant), SUKSES, VALUE } \\
\text { c. Predictors: (Constant), SUKSES, VALUE, ASPIRATION } \\
\text { d. Predictors: (Constant), SUKSES, VALUE, ASPIRATION, DEFENCES } \\
\text { e. Predictors: (Constant), SUKSES, VALUE, ASPIRATION, DEFENCES, AFFILIATIVE } \\
\text { f. Predictors: (Constant), SUKSES, VALUE, ASPIRATION, DEFENCES, AFFILIATIVE, } \\
\text { ENHANCING } \\
\text { g. Predictors: (Constant), SUKSES, VALUE, ASPIRATION, DEFENCES, AFFILIATIVE, } \\
\text { ENHANCING, AGRESIVE }\end{array}$} \\
\hline \multicolumn{10}{|c|}{$\begin{array}{l}\text { h. Predictors: (Constant), SUKSES, VALUE, ASPIRATION, DEFENCES, AFFILIATIVE, } \\
\text { ENHANCING, AGRESIVE, DEFEATING } \\
\text { i. Predictors: (Constant), SUKSES, VALUE, ASPIRATION, DEFENCES, AFFILIATIVE, } \\
\text { ENHANCING, AGRESIVE, DEFEATING, JENISKELAMIN }\end{array}$} \\
\hline
\end{tabular}

Berdasarkan data pada tabel 4 dapat disampaikan informasi sebagai berikut:

1. Variabel success memberikan sumbangan sebesar $6 \%$ dalam varians psychological well-being. Sumbangan tersebut signifikan dengan $\mathrm{F}$ Change $=17,177$ dan $\mathrm{df} 1=1$ dan $\mathrm{df} 2=270$ dengan Sig.F Change $=$ $0,000(\mathrm{p}<0,05)$.

2. Variabel values memberikan sumbangan sebesar $3,7 \%$ dalam varians psychological well-being. Sumbangan tersebut signifikan dengan $\mathrm{F}$ Change $=11,120$ dan $\mathrm{df} 1=1$ dan $\mathrm{df} 2=269$ dengan Sig.F Change $=$ $0,001(\mathrm{p}<0,05)$.

3. Variabel aspiration memberikan sumbangan sebesar $0,2 \%$ dalam varians psychological well-being. Sumbangan tersebut tidak signifikan dengan $\mathrm{F}$ Change $=0,647$ dan $\mathrm{df} 1=1$ dan $\mathrm{df} 2=268$ dengan Sig. $\mathrm{F}$ Change $=0,422(\mathrm{p}>0,05)$.

4. Variabel defences memberikan sumbangan sebesar $0,2 \%$ dalam varians psychological well-being. Sumbangan tersebut tidak signifikan dengan $\mathrm{F}$ Change $=0,530$ dan $\mathrm{df} 1=1$ dan $\mathrm{df} 2=267$ dengan Sig. $\mathrm{F}$ Change $=0,467(p>0,05)$. 
5. Variabel affiliative humor memberikan sumbangan sebesar $3,4 \%$ dalam varians psychological well-being. Sumbangan tersebut signifikan dengan $\mathrm{F}$ Change $=10,600$ dan df $1=1$ dan df $2=266$ dengan Sig. $F$ Change $=0,001(\mathrm{p}<0,05)$.

6. Variabel self-enhancing humor memberikan sumbangan sebesar $0,1 \%$ dalam varians psychological well-being. Sumbangan tersebut tidak signifikan dengan $\mathrm{F}$ Change $=0,204$ dan $\mathrm{df} 1=1$ dan $\mathrm{df} 2=265$ dengan Sig.F Change $=0,652(p>0,05)$.

7. Variabel aggressive humor memberikan sumbangan sebesar $1,4 \%$ dalam varians psychological well-being. Sumbangan tersebut signifikan dengan $\mathrm{F}$ Change $=4,293$ dan $\mathrm{df} 1=1$ dan $\mathrm{df} 2=264$ dengan Sig. $\mathrm{F}$ Change $=0,039(p<0,05)$.

8. Variabel self-defeating humor memberikan sumbangan sebesar $3,7 \%$ dalam varians psychological well-being. Sumbangan tersebut signifikan dengan $\mathrm{F}$ Change $=12,131$ dan $\mathrm{df} 1=1$ dan $\mathrm{df} 2=263$ dengan Sig. $\mathrm{F}$ Change $=0,001(p<0,05)$.

9. Variabel jenis kelamin memberikan sumbangan sebesar $0,4 \%$ dalam varians psychological well-being. Sumbangan tersebut tidak signifikan dengan $\mathrm{F}$ Change $=1,448$ dan $\mathrm{df} 1=1$ dan $\mathrm{df} 2=262$ dengan Sig. $\mathrm{F}$ Change $=0,230(p>0,05)$.

Dengan demikian, bahwa terdapat lima IV dari sembilan IV, yaitu successes, values, affiliative humor, aggressive humor dan self-defeating humor yang mempengaruhi psychological well-being secara signifikan jika dilihat dari besarnya R2 yang dihasilkan dari sumbangan proporsi variabel yang diberikan.

\section{KESIMPULAN DAN SARAN}

\section{Diskusi}

Hasil penelitian tersebut mendukung penelitian terdahulu yang dilakukan oleh Marshall dan Brown (dalam Jonathon D., 2010) yang mengatakan bahwa ada korelasi antara self-esteem dengan kesehatan dan psychological well-being dalam menghadapi berbagai ancaman psikologis. Pyszczynski (dalam Kristin D., 2011) menjelaskan bahwa self-esteem menjadi pencegah terjadinya kecemasan yang membantu menjaga psychological wellbeing dan membantu dalam proses coping.

Dari penelitian sebelumnya dapat disimpulkan bahwa slef-esteem berperan penting dalam menjaga psychological well-being. Hal tersebut didukung oleh penelitian Clay, Brian, Jacob, Constantine, Christie dan Liao (2010) yang menyatakan bahwa self-esteem mempengaruhi psychological well-being dalam mengatasi kecemansan akan kematian. Namun, dari hasil penelitin ini ditemukan hal yang menarik berkaitan dengan selfesteem, 
dimana tidak semua dimensi dari selfesteem memiliki pengaruh yang signifikan terhadap psychological well-being. Terbukti dalam penelitian ini, tiga dari empat dimensi self-esteem yaitu successes, aspirations dan defences memiliki $P$-value $(\mathrm{p}>0,05)$ yang artinya dimensi tersebut tidak memiliki pengaruh secara signifikan, hanya dimensi values yang memiliki $P$-value $0,003(p<0,05)$ atau signifikan terhadap psychological well-being.

Dimensi values pada siswa SMAN 72 dapat berpengaruh secara signifikan terhadap psychological well-being karena, bila melihat pada tabel kategorisasi values, $53,3 \%$ siswa pada sampel penelitian ini memiliki skor values yang tinggi. Values atau nilai-nilai sejatinya sudah ada didalam diri individu, terinternalisasi dari lingkungan. Lingkungan disini artinya adalah interaksi sosial antara individu dengan orang-orang yang ada disekitarnya seperti orang tua dan teman sebaya. Individu dengan skor values yang tinggi berarti ia dapat menerima standar nilai-nilai yang ada dikelompoknya. Penerimaan standar nilai dari kelompok berkaitan erat dengan hubungan positif dengan orang lain (positive relation with others) yang merupakan salah satu dimensi dari psychological well-being. Berdasarkan alasan tersebut dapat menjelaskan mengapa dimensi values dapat berpengaruh secara signifikan terhadap psychological well-being.

Berdasarkan nilai koefisien regresi dimensi values memiliki nilai koefisien regresi yang positif $(+2.967)$ yang artinya values memiliki pengaruh positif yang signifikan terhadap psychological well-being. Dengan demikian dapat disimpulkan, semakin tinggi values maka semakin tinggi psychological well-being. Hasil penelitian ini dengan diperkuat dengan teori dari Coopersmith (1990) yang mengatakan bahwa values atau nilai-nilai dapat menginternalisai ke dalam diri manusia melalui orang tua dan figurfigur signifikan lainnya dalam hidup. Oleh karena sebab itu penting bagi orang tua atau guru untuk menanamkan nilai-nilai luhur kepada anakanaknya, agar tertanam dalam diri mereka nilai-nilai positif sehingga akan berdapak kepada meningkatnya psychological well-being.

Coopersmith (1990) menambahkan selain orang tua dan figur signifikan lainya, lingkungan turut mempengaruhi values. Interaksi yang terjadi antara individu dengan lingkungan akan membawanya untuk menerima standar nilai dan standar nilai tersebut menjadi prinsip dasar untuk menilai keberartian dirinya. Faktor-faktor seperti penerimaan lingkungan dan perhatian orang tua merupakan hal-hal yang dapat memperkuat penerimaan values. Salah satu alasan mengapa siswa yang menjadi sampel dalam penelitian ini memiliki kategorisasi values yang tinggi. Hal ini tidak terlepas dari peran serta orang tua dan guru yang telah menanamkan nilai-nilai yang positif kepada anak-anaknya dan terinternalisasi dengan baik dalam diri mereka sehingga dalam penelitian ini dimensi values memiliki pengaruh yang signifikan terhadap psychological wellbeing. 
Dimensi-dimensi lain yang tidak signifikan dari variabel self-esteem adalah successes, aspiration dan defences. Hal ini mungkin terjadi karena pada penelitin ini peneliti tidak menggunakan instrumen baku milik Coopersmith (1990) sepenuhnya. Peneliti melakukan modifikasi pada instrumen baku pengukuran self-esteem milik Coopersmith (1990) dengan hanya menggunakan delapan dari dua puluh lima item baku yang ada dan tujuh belas item lainya peneliti membuatnya sendiri berdasarkan indikator dari teori. Bila berdasarkan data pada tabel 4.6 dan 4.9, sampel pada penelitian ini memiliki skor kategorisasi successes dan defences yang rendah. Kategori successes pada sampel penelitian ini rendah, mungkin salah satu penyebabnya adalah karena siswa SMAN 72 yang menjadi sampel pada penelitian ini tidak memiliki keyakinan yang kuat bahwa mereka mampu bersaing dan menjadi lebih sukses seperti siswa pada sekolah unggulan lainnya. Hal tersebut mungkin dapat menajadi alasan lain mengapa dimensi successes dan defences pada sampel penelitian tidak memiliki pengaruh yang signifikan terhadap psychological well-being.

Dimensi berikutnya yang memiliki pengaruh signifikan terhadap psychological well-being adalah affiliative humor, aggressive humor dan selfdefeating humor pada variabel humor style. Hal tersebut sejalan dengan penelitian terdahulu yang dilakukan oleh Kuiper (dalam Nicholas, Grimshaw, Leite dan Kirsh, 2004) yang menyatakan bahwa ada hubungan antara humor style dengan psychological well-being. Namun dalam hasil penelitiannya ternyata tidak semua jenis humor style berkorelasi positif dengan psychological well-being. Diantaranya aggressive humor dan self-defeating humor memiliki korelasi yang negatif dengan psychological well-being, tetapi dua jenis humor style lainya yaitu affiliative humor dan slef-enhancing humor memiliki korelasi yang positif.

Dari hasil penelitin ini ditemukan perbedaan dengan penelitian terdahulu yang dilakukan oleh Kuiper (dalam Nicholas, Grimshaw, Leite dan Kirsh, 2004) yang menarik untuk dibahas dan dianalisis lebih dalam. Dalam penelitian ini jenis self-enhancing humor ternyata tidak berpengaruh secara signifikan terhadap psychological well-being. Hal tersebut dapat dimungkinkan terjadi karena berdasarkan data pada tabel kategorisasi selfenhancing humor, 55,1\% sampel memiliki self-enhancing humor yang rendah. Self-enhancing berkaitan dengan penggunaan perspektif humor sebagai regulasi emosi atau mekasinme coping saat menghadapi stres (Martin, 2007).

Bila dilakukan analisis lebih dalam terhadap item-item yang digunakan untuk mengukur self-enhancing humor, pada item nomer enam terdapat kata yang mungkin sulit untuk dipahami oleh sampel, contohnya kata "terhibur dengan keabsurdan hidup" atau dalam item aslinya "amused by the absurdities of life". Kata yang sulit dipahami tersebut mungkin mengakibatkan sampel salah dalam mengintepretasikan item. Hal ini mungkin menjadi salah satu penyebab mengapa hasil dari penelitian ini tidak sejalan dengan penelitian terdahulu. 
Selanjutnya pada penelitian ini terbukti bahwa affiliative humor memiliki pengaruh positif yang signifikan terhadap psychological well-being. Artinya semakin tinggi affiliative humor maka tinggi pula psychological wellbeing. Hal tersebut tentunya sejalan dengan teori Martin (2007) yang menyatakan bahwa affiliative humor dan self-enhancing humor merupakan humor yang adaptif atau memiliki dampak positif bagi penggunanya, salah satunya adalah meningkatkan psychological well-being.

Selain itu ditemukan juga ketidaksesuaian antara penelitian terdahulu yang dilakukan Kuiper (dalam Nicholas, Grimshaw, Leite dan Kirsh, 2004) dengan hasil penelitian ini. Dalam penelitiannya Kuiper (2004) menyebutkan bahwa aggressive humor tidak memiliki pengaruh yang positif dengan psychological well-being, namun dalam penelitian ini ditemukan hasil yang berbeda. Berdasarkan hasil uji regresi yang dilakukan, aggressive humor memiliki pengaruh positif yang signifikan dengan psychological well-being. Artinya dalam penelitian ini tingginya aggressive humor ternyata tidak membuat psychological well-being pada seseorang menjadi rendah.

Hal tersebut tentu saja sangat bertolak belakang dengan teori Martin (2007) yang menyebutkan bahwa aggressive humor dan self-defeating humor merupakan humor yang maladaptif atau memiliki dampak buruk bagi penggunanya. Salah satu dampaknya adalah dapat menurunkan psychological well-being. Penelitian ini menjadi tidak sejalan dengan teori tersebut dikarenakan dari hasil uji CFA pada item yang mengukur aggressive humor ditemukan banyak item yang tidak valid. Item-item yang tidak valid tersebut mengakibatkan instrumen yang disusun menjadi kurang mewakili variabel, sehingga mengurangi nilai prediksi dan keakuratannya.

Selain itu, Michael Mulkay (dalam Martin, 2007) mengemukakan bahwa fungsi lelucon mungkin lebih berkaitan dengan ekspresi sosial, topiknya biasa dianggap tabu oleh budaya. Topik tabu seperti humor seks dan agresif sering diangap tidak pantas dikatakana pada situasi normal. Namun topik lelucon seperti itu dapat diterima oleh lingkungan sosial karena dalam arti "hanya bercanda" atau tidak dianggap serius. Fenomena tersebut yang mungkin saja yang terjadi pada remaja yang menjadi sampel dalam penelitian ini, dimana bentuk aggressive humor seperti mencemooh, mengejek dan menyidir sudah menjadi hal yang biasa dilakukan dalam mengekspresikan rasa humor mereka. Didukung dengan data pada tabel kategorisasi aggressive humor, ternyata 54\% sampel memilik aggressive humor yang tinggi. Pernedaan situasi lingkungan sosial yang ada pada remaja itu lah yang mungkin menjadi salah satu penyebab hasil dari penelitian ini berbeda dengan tengan teori yang ada.

Jenis humor style berikutnya yang memiliki pengaruh negatif yang signifikan adalah self-defeating humor dengan psychological well-being. Hal ini sejalan dengan teori Martin (2007), dimana Ia mengatakan bahwa selfdefeating humor bersifat sangat menghina diri sendiri, berusaha untuk menghibur orang lain dengan melakukan atau mengatakan hal-hal yang 
lucu mengenai aib diri sendiri. Menurut Martin (2007) humor style tersebut termasuk dalam maladaptif humor yang dapat memberikan dampak negatif, salah satunya adalah dapat menurunkan psychological well-being bagi orang yang menggunakannya.

Variabel terakhir yang tidak memiliki pengaruh signifikan terhadap psychological well-being adalah jenis kelamin. Pada tabel koefisien regresi jenis kelamin memiliki $P$-value $0,230(\mathrm{p}>0,05)$ atau tidak signifikan. Hasil penelitian ini sejalan dengan penelitian terdahulu yang dilakukan oleh Creed dan Watson (2003). Dimana, dalam penelitiannya Ia meneliti apakah ada perbedaan antara pria dan wanita pada interaksi bekerja dan manfaat nyata dari bekerja sebagai prediktor psychological well-being. Hasilnya, ternyata tidak ada perbedaan yang signifikan tingkat psychological well-being antara pria dan wanita.

Jeannie (2012) juga memperkuat hasil temuan dari penelitian ini. Ia menyebutkan bahwa tidak ada perbedaan yang signifikan pada seluruh dimensi dari psychological well-being antara pria dan wanita. Perbedaanya pada wanita memiliki skor yang lebih rendah pada dimensi otonomi dibandingkan dengan pria.

\section{Saran}

Peneliti menyadari bahwa dalam penelitian ini tidak lepas dari kekurangan. Oleh karena itu peneliti membagi saran menjadi dua, yaitu saran metodologis dan saran praktis. Agar dapat dijadikan pertimbangan bagi penulis selanjutnya dan masukan bagi pembaca, siswa, orang tua dan guru sehingga dapat mengambil manfaat dari penelitian ini.

\section{Saran Metodologis.}

1. Pada penelitian ini, sampel yang digunakan hanya di satu sekolah yaitu SMAN 72 Jakarta. Saran bagi penelitian selanjutnya, agar menggunakan sampel dari beberapa sekolah yang berbeda atau pada subjek penelitian lain seperti mahasiswa, sehingga mampu mendapatkan gambaran lain di luar penelitian ini.

2. Untuk penelitian selanjutnya, disarankan untuk memperbanyak jumlah sampel yang dilibatkan dan menggunakan faktor demografis yang lain seperti usia, agar hasil penelitian yang dilakukan lebih representatif.

3. Pada penelitian ini, peneliti menggunakan skala baku self-esteem milik Coopersmith (2011) yang telah dimodifikasi. Dari hasil uji validitas konstruk skala self-esteem tersebut, ditemukan ada beberapa item yang tidak valid. Oleh karena itu, untuk penelitian selanjutnya jika ingin menggunakan self-esteem sebagai independent variable dalam penelitiannya disarankan untuk menggunakan skala baku lain, seperti skala yang dikembangkan oleh Rosenberg (1985) atau Minchinton (1993). Karena dari beberapa hasil penelitian terdahulu 
mengatakan bahwa alat ukur yang mereka kembangkan memliki tingkat validitas yang tinggi.

4. Dari hasil penelitian ini ditemukan bahwa self-esteem, humor style dan jenis kelamin memiliki pengaruh yang signifikan terhadap psychological well-being sebesar $19,2 \%$ dan $80,8 \%$ lainya dipengaruhi oleh variabel lain di luar penelitian ini. Sehingga saran bagi penelitian selanjutnya, agar menambahkan variabel lain yang memiliki pengaruh terhadap psychological well-being seperti kepuasan hidup, spiritualitas, optimisme, kebahagiaan, kepuasan hidup, status sosial, dukungan sosial dan kedewasaan.

\section{Saran Praktis}

1. Dari hasil penelitian ini ditemukan bahwa self-esteem memiliki pengaruh yang signifikan terhadap psychological well-being. Sehingga diharapkan bagi guru untuk meningkatkan selfesteem peserta didiknya dengan cara, menanamkan nilai-nilai luhur pada siswanya, menghargai usaha sekecil apa pun yang dilakukan oleh siswa, memberikan pujian kepada siswa yang berprestasi dan memberikan arahan kepada siswanya mengenai cita-cita dan orientasi tujuan hidup mereka.

2. Saran lain bagi guru, humor juga dapat diaplikasikan dalam dunia pendidikan. Salah satu contohnya adalah sebagai metode ice breaking saat sebelum memulai suatu pelajaran. Dengan menggunakan metode tersebut peserta didik akan merasa lebih tenang, terciptanya suasana belajar yang lebih dinamis dan siswa menjadi lebih termotivasi.

3. Dari hasil penelitian ini juga ditemukan bahwa self-defeating humor memiliki pengaruh negatif yang signifikan terhadap psychological well-being. Dengan demikian dapat disimpulkan, semakin rendah selfdefeating humor maka semakain tinggi psychological well-being. Sehingga saran bagi para siswa untuk tidak menggunakan selfdefeating humor dalam kesehariannya, karena jenis humor tersebut termasuk dalam maladaptif humor yang memiliki dampak negatif bagi penggunanya.

4. Saran bagi para orang tua agar memberikan pengertian dan penjelasan kepada anak-anaknya, bahwa melontarkan sindiran, ejekan, cemooh, meremehkan orang lain atau bentuk aggressive humor lainnya dalam keseharian bukan lah sesuatu yang dapat diangap wajar dan lucu. Hal tersebut tentunya memiliki dampak buruk bagi anak terkait dengan interaksi hubungan sosialnya. 


\section{DAFTAR PUSTAKA}

Alicia D., Peter J., (2002), A Theory of Self-Esteem, The University of North Carolina Press, Social Forces, 80(3):1041-1068.

Brett R., Doret k., Marie P., (2003), Gender differences in aspects of psychological well-being, South African Journal of Psychology 33(4), 212-218, South Africa.

Clay R., Brian O., Jacob J., Constantine S., Christie C., Jiangqun L., (2010). Adjusting to Death: The Effects of Mortality Salience and SelfEsteem on Psychological Well-Being, Growth Motivation, and Maladaptive Behavior, American Psychological Association, Journal of Personality and Social Psychology 2010, Vol. 99, No. 6, 897-916.

Coopersmith S., (1990), The Antecedents of Self-Esteem, Consulting Psychologists Press.

Coopersmith, S., (1997), Coopersmith self-esteem inventory - The antecedents of self-esteem, W. H. Freeman \& Co, San Francisco.

Demo, David H. (1985). The measurement of self-esteem: Refining our methods, Journal of Personality and Social Psychology, 48, 1490-1502.

Giovanni A. Fava, Chiara R., (2003), Development and characteristics of a wellbeing enhancing psychotherapeutic strategy: well-being Therapy, Pergamon, Journal of Behavior Therapy and Experimental Psychiatry 34 (2003) 45-63.

Herz, L.\& Gullone E., (1999), Coopersmith Self-Esteem Inventory-The School Form (SEI), Psychosocial Measures for Asian Americans: Tools for Practice and Research, Columbia.

Hills, P. R., Francis, L. J., \& Jennings, P., (2011), Revised School Short Form Coopersmith Self-Esteem Inventory, American Psychological Association, Retrieved from PsycTESTS. doi: 10.1037/t05656-000.

James A. Thorson and Powell F., Ivan S, William P., (1997) Psychological Health and Sense ol Humor, John Wiley \& Sons, Inc, J Clin Psychol 53: 605-619.

Jeannie A. Perez, (2012), Gender Difference in Psychological Well-being among Filipino College Student Samples, International Journal of Humanities and Social Science, Vol. 2 No. 13. 
Jonathon D. Brown, (2010), Across the (Not So) Great Divide: Cultural Similarities in Self-Evaluative Processes, Social and Personality Psychology Compass 4/5 : 318-330, 10.1111/j.17519004.2010.00267.x.

Juliet H., Tom C., Steven M., (2011), Mental Health Promotion in Work Place - A Good Practice Report, European Agency for Safety and Health at Work, Luxembourg.

Kathryn J., (2002), Report and Literature review into the role of self-esteem as a barrier to learning and as an outcome, Niance, Department for education and skill.

Katy W. Liu, (2012), Humor Styles, Self-Esteem and Subjective Happiness, Discovery - SS Student E-Journal, Vol. 1, 2012, 21-41.

Keyes Corey L., Shmotkin D., Ryff Carol D., (2002), Optimizing Well-Being: The Empirical Encounter of Two Traditions, the American Psychological Association, Inc., Journal of Personality and Social Psychology, 2002, Vol. 82, No. 6, 1007-1022.

Kristin D. Neff, (2011), Self-Compassion, Self-Esteem, and Well-Being, Social and Personality Psychology Compass 5/1 (2011): 1-12, $10.1111 /$ j.1751-9004.2010.00330.x.

Mardiya, (2011), Persoalan depresi pada remaja, Advokasi Konseling dan Pembinaan Kelembagaan Keluarga Berencana dan Kesehatan Reproduksi BPMPDP dan KB, Kulon Progo.

Martin Rod A. (2004), Sense of humor and physical health: Theoretical issues, recent findings, and future directions, Walter de Gruyter, Humor 17-1/2 (2004), 1-19.

Martin Rod A. (2007), The Psychology of Humor: An Integrative Approach, Elsevier Academic Press, Burlington USA.

Martin Rod A., (2007), Sense of Humor, University of Western Ontario London.

Martin, R. A., Puhlik-Doris, P., Larsen, G., Gray, J., \& Weir, K. (2003), Humor Styles Questionnaire, American Psychological Association, PsycTESTS. doi: 10.1037/t07239-000.

Maulina S. (2009), Hubungan Antara Religiusitas dengan Psychological wellbeing pada Lansia, Fakultas Psikologi, Universitas Gunadarma, Jakarta. 
Nicholas Kuiper, Grimshaw M., Leite Catherine., Kirsh Gillian., (2004), Humor is not always the best medicine: Specific components of sense of humor and psychological well-being, Walter de Gruyter, Humor 17-1/2 (2004), 135-168.

Norman M. Bradburn, (1969), The Structure of Psychological Well-being, ALDINE Publishing Company 529 South Wabash Avenue Chicago, Illions 60605.

Papallia E. (2007). Human Development $9^{\text {th }}$ Edition. Ney York: McGraw-Hill International.

Peter A. Creed, Tania W., (2010) Age, gender, psychological well-being and the impact of losing the latent and manifest benefits of employment in unemployed people, Associate Professor Peter A. Creed School of Applied Psychology GriffithUniversity, Gold Coast Australia.

Pramudiarja, (2012), Dibanding Kecelakaan, Depresi Lebih Banyak Picu Kelumpuhan, detikHealth, Jakarta.

Richard A. B., Machin A., (2006), Investigating The Structural Validity of Ryyf's Psychological Well-being Scale across Two Sample, Department of Psychology University of Southern Queensland, Australia.

Robert A. Emmons, (2003), Personal Goals, Life Meaning, and Virtue: Wellsprings of A Positive Life, Department of Psychology HKU, Hong Kong.

Rosenberg, (2000), Theoretical Definitions Self-esteem, Wordpress Journal, Kannapolis, NC, United States

Ryff Carol D., Burton S., (1996), Psychological Well-Being: Meaning, Measurement, and implications for Psychotherapy Research, Karger AG, Mad sonW, I 53706 (USA).

Samman E., (2007), Psychological and Subjective Well-being: Proposal for Internationally Comparable Indicators, Oxford Poverty \& Human Development Initiative (OPHI) Department of International Development, Queen Elizabeth House, Oxford.

Snyder C. \& Lopez J. (2002). Handbook of Positive Psychology. New York: Oxford University Pess Inc. 
Tayfun D., Tar1k T., Fatma S., (2013), The Role of Self-esteem, Psychological well-being, Emotional Self-Efficacy and Affect Balance on Happiness: A Path Model, European Scientific Journal, edition vol.9, No.20 ISSN: 1857 - 7881 (Print) e - ISSN 1857- 7431. 
